\title{
Caída y exilio como motivos en EI sueño del ángel, de Gloria Elena Espinoza ${ }^{1}$
}

\author{
Jorge Ramírez Caro \\ Universidad Nacional, Costa Rica
}

\section{RESUMEN}

Se muestra que la novela El sueño del ángel, de la nicaragüense Gloria Elena Espinoza, se articula narrativamente alrededor de una serie de caídas, que afectan a los personajes. Son caídas que abarcan varios niveles: el natural, el antropológico, el axiológico y el divino; además, es una caída planteada desde una perspectiva milenarista y apocalíptica, que manifiesta una visión del mundo terrenal como corrupto y en decadencia. Se señala la condición del ángel caído (o exiliado) como una metáfora de la condición humana, asociada al desarraigo y a la derrota.

\begin{abstract}
It is shown how the Nicaraguan novel El sueño del ángel [The angel's dream] by Gloria Elena Espinoza is narrated around a series of falls affecting the characters. These falls span several levels: natural, anthropological, axiological and divine. The falls are also seen from a millenary and apocalyptical perspective, which sets forth a view of life on earth as corrupt and decadent. The condition of the fallen (or exiled) angel is explored as a metaphor for the human condition, related to alienation and defeat.
\end{abstract}

Palabras clave: literatura nicaragüense, novela nicaragüense, novela histórica, interpretación del textos.

Keywords: Nicaraguan literature, Nicaraguan novel, historical novel, text interpretation.

${ }^{1}$ Recibido: 1 de febrero 2009; aceptado: 3 de marzo 2009.

${ }^{2}$ Correo electrónico: caronauta@ hotmail.com

$$
\text { LETRAS } 45 \text { (2009), ISSN 1409-424X }
$$


La trama de El sueño del ángel, de Gloria Elena Espinoza ${ }^{3}$, se resume así: al mismo tiempo que un ángel es exiliado del cielo y tiene pesadillas, José vuelve desde Miami a Nicaragua después de veinte años de exilio, a propósito de la revolución sandinista en la que ha participado Augusta, que ha permanecido inxiliada en su propia tierra. A estos personajes los asalta el pasado de modos diferentes: a José por medio de extrañas voces que dice oír y que le revelan situaciones familiares presentes y futuras; a Augusta por visiones y asaltos de las sombras del pasado que vuelven. Ambas experiencias se enlazan con una cadena de sucesos naturales e históricos que tienen en común la destrucción y la muerte: terremotos, huracanes, inundaciones, dictadura y revolución sandinista. A José y Augusta se les suma don Fito que viene a completar el cuadro de las consecuencias de los mencionados sucesos, leídos unos como la expresión de que el fin del mundo está próximo (visión apocalíptica de la realidad) y otros como la expresión de la utopía humana de la justicia social (ideal traicionado por los dirigentes revolucionarios que llegaron al poder, con el saldo del martirio de muchos, el hambre, la miseria para el pueblo y el exilio para los detractores). Así don Fito acompaña la visión apocalíptica de José y Victoria el ostracismo de Augusta.

Sobresale el paralelismo entre la historia del ángel y la de los exiliados: tanto el ser angélico como los humanos son arrancados de su lugar de origen. Eso da pie para que el exilio adquiera un doble sentido: uno tiene que ver con el desarraigo físico y otro con el psicológico. El primero se refiere a ser arrancado de su propia tierra y el segundo a inxiliarse en el propio territorio o en el propio mundo interior, como leemos en el preámbulo de la novela: «El exilio te arrebata del nido, de tu tierra o te confina hacia arduos laberintos del alma» (8). Quienes vuelven del extranjero (José y Victoria) se vienen por el hilo de los recuerdos sugerido por la poesía y la música, y quienes vuelven en sí lo hacen

\footnotetext{
${ }^{3}$ Gloria Elena Espinoza, El sueño del ángel (Managua: Distribuidora Cultural, 2003); en adelante, para esta obra se indicará el número de página entre paréntesis. 
también por medio de ráfagas de imágenes dolorosas que no quisieran desenterrar de la memoria. José y Victoria vienen a encontrarse con el mundo que dejaron; Augusta quisiera deshacerse del mundo que la posee, la angustia, la ahoga y la martiriza: su vinculación con el sandinismo, sus aventuras amorosas y la muerte de muchos seres queridos. Al final todos se curan de sus males presentes, la angustia se convierte en calma y la tristeza en alegría: José vuelve sano y alegre a Miami, el ángel volverá a la tierra, no en calidad de exiliado, sino como ángel de la guarda de un niño que nacerá en Miami; Victoria y Augusta se cuentan sus pasados amorosos y políticos y sus «almas hasta ahora prisioneras de sí mismas, volaron como palomas» (131).

Varios aspectos se resaltan aquí de El sueño del ángel: a. el paratexto, editorial y autorial: portada, títulos y epígrafes; b. la relación de don Fito con don Quijote; c. el carácter milenarista de una novela circunscrita al cronotopo apocalíptico; d. el mundo erótico de Augusta; y e. la persistencia de lo fantástico. Nuestro acercamiento a esta novela es provisional: dejará abiertas muchas puertas y procurará incitar-provocar a otros lectores que aten los cabos sueltos y aportar otros hilos de lectura, para que otros futuros lectores tengan un tejido más poroso y alcancen otros destellos de la luz que siempre quedan titilando en el fondo de aquello que Barthes llama la zona ilegible.

\section{Los paratextos ${ }^{4}$}

Los paratextos editoriales de esta novela los limitaremos a las imágenes presentes en la tapa y en la contratapa. En ambos espacios las imágenes ponen de manifiesto dos movimientos básicos: uno de caídaexilio y otro de ascenso-retorno, respectivamente. La tapa representa el momento de la caída del ángel a un lugar desolado, desértico. No se trata solo de la oposición cielo-arriba / tierra-abajo, sino también, como

\footnotetext{
${ }^{4}$ Para una comprensión del concepto paratexto, ver Saïd Sabia, «Paratexto. Títulos, dedicatorias y epígrafes en algunas novelas mexicanas», Espéculo. Revista de estudios literarios 31 (2005).
} 
veremos más adelante, de la antinomia Miami-allá / Nicaragua-acá. El ángel se muestra espalda al lector, observa un cielo roto que deja ver a una serpiente que se esconde tras un planeta. Esta imagen remite a varios elementos intertextuales e interdiscursivos sobre la batalla en los cielos de las huestes angélicas y la expulsión del ángel malo, arrojado a la tierra. Pero la imagen del paratexto invierte la semiótica cultural inscrita en nuestro sistema de referencias: la serpiente, símbolo del mal, queda en el espacio superior y el arrojado es un ser divino, cuya mirada hacia el cielo deja abierta la añoranza-nostalgia del paraíso. Llama la atención el hecho de que el lugar donde el ángel posa su pie adquiera movimiento: lo desértico parece recobrar vida, las arenas simulan ser agua que giran en círculos concéntricos. ¿El ser angélico posee aún poder para generar vida?

La contratapa nos ubica en el viaje de ascenso del ángel: del mismo lugar desértico donde cayó se elevará a los cielos por medio de una escalera de fuego. No estamos ante un ser antropomórfico, sino ante un ser transfigurado. En lugar de un solo hueco en el cielo, nos encontramos con dos: uno que deja ver una galaxia y otro hacia donde se yergue una escalera. En lugar del planeta y la serpiente escondida tras él, estamos ante una luz en la que se pierde el extremo superior de la escalera por donde se dispone a subir el ángel. De una nube cuelga un ala. También esta imagen evoca elementos intertextuales e interdiscursivos relacionados con la escala de Jacob y con la transfiguración de Cristo en el monte Tabor. La posibilidad de generar vida en aquel ángel antropomórfico de la tapa no aparece en este ángel transfigurado: el lugar de donde parte queda incólume, desértico, árido. El mundo parece no haber obtenido ningún beneficio, ninguna bendición con aquel ser celeste que lo ha visitado y ahora vuelve a su lugar de origen.

Vistos ambos espacios, estamos ante dos momentos de la vida del ángel: frente a su exilio o desarraigo de su mundo celeste y ante el proyecto de su retorno a su patria, a su nido. Estos elementos paratextuales encuentran su confirmación en la lectura de la novela, tanto en los personajes humanos como en el ente divino, como ya hemos 
adelantado. Este paratexto no sólo sirve para hablar del viaje del ángel, sino también del viaje de retorno e ida de José, equiparado al ángel en varios trayectos de la novela, como veremos.

\section{Titulología}

Pasemos a los paratextos autoriales. Dado el carácter proyectivo del título de la novela, podemos platear varias hipótesis sobre el sueño del ángel. Podríamos suponer que el sueño gira en torno a algunos de estos tópicos: la humanización del ángel, la recuperación de la sexualidad, su liberación de las leyes celestiales, su matrimonio con una criatura terrestre, etc. Después de leído el texto, llegamos a las siguientes conclusiones: a. que la historia del ángel es una historia paralela a la de José y Augusta; b. que el ángel es un elemento secundario dentro del texto; y c. que su sueño resulta ser muy banal: ser el ángel de la guarda de un niño que va a nacer en Miami. Podemos intentar leer el título con los elementos paratextuales señalados: según la tapa y la contratapa el sueño del ángel sería volver y reintegrarse a su espacio celeste después de su caída-exilio, tal como sucede también con José, con quien guarda estrecha relación, como ahondaremos más adelante.

Es probable que este primer acercamiento al texto nos señale algunas coordenadas a partir de las cuales podamos ingresar a otros núcleos significativos dentro de los dos planos que se convocan en el título: el vertical y el horizontal, es decir, el divino-celeste y el humanoterrestre, dado que el sueño sólo puede darse en una dimensión espaciotemporal. Esto último nos llevaría a considerar el juego espacio-temporal vinculado con los personajes y con la semiótica del texto presente tanto en los títulos de capítulos como en los epígrafes. Tomemos en cuenta primero algunos nombres de capítulos para después ingresar a los epígrafes.

Los primeros seis capítulos sitúan el texto en una atmósfera maravillosa que tiende hacia lo fantástico. Nos ponen en contacto con los personajes centrales de la narración y dejan adivinar parte de la historia que apenas se está abriendo para el lector. Por ejemplo, el capítulo uno 
nos introduce al espacio de la duda con su «Aparentemente» y luego al campo de lo maravilloso con la mención del «ángel». De entrada, el título nos desconcierta: «Aparentemente el ángel que nos ocupa está exiliado del cielo y sufre pesadillas» (9). Se nos sugiere que somos poseídos por un ángel exiliado y que el espacio que somos le produce pesadilla. Sobresale la oposición espacial cielo (lugar de deleite, tranquilidad y seguridad para el ángel) / nosotros (lugar de tormento, pesadilla, extravío y desconcierto para el ángel $)^{5}$. Las preguntas que me surgen de este título son: ¿Acaso somos un infierno para el ángel? ¿Es nuestra alma un infierno?

El segundo capítulo empata temáticamente con el primero, además de relacionar a José con el ángel, ambos exiliados de su lugar de origen: «José y Amparo realizan el primer viaje a su patria desde que se exiliaron en Miami. A José le ocurre algo misterioso en el avión» (11). También nos recuerda el elemento maravilloso por medio de «A José le ocurre algo misterioso». Al querer empatar la diégesis desplegada por el primer capítulo, uno supone que lo «misterioso» que le sucede a José tiene que ver con el ángel. Es más, puede llegarse a pensar que el alma en la que está exiliado el ángel es la de José, razón por la cual sufre los trastornos y las visiones que se describen en la novela. De nuevo encontramos la oposición espacial: Allá-Miami, sin trastornos, lugar de tranquilidad y bienestar / Acá-patria, con trastornos, sin tranquilidad ni bienestar. Este «algo misterioso» puede equipararse a las «pesadillas» sufridas por el ángel, cuestión que reforzaría la relación José-Ángel.

El tercer capítulo nos mantiene dentro de la atmósfera de lo maravilloso: «José continúa oyendo en su viaje una voz que lo desconcierta». Este desconcierto no es privativo de José, sino también de nosotros como lectores, ya que nos incita a pensar que, como adelantamos, el ángel está exiliado en José, mucho más cuando vemos que experimenta visiones, procesos de desmaterialización,

\footnotetext{
${ }^{5}$ Esta oposición espacial guarda relación con la establecida entre el allá y el acá de Miami/Nicaragua. Todo lo asociado con el allá estará valorado positivamente, mientras que el acá tendrá una valoración negativa, como empezamos a ver desde el capítulo II. 176
} 
afantasmamiento, adquiere la capacidad de atravesar paredes, es decir, se angeliza. Esto nos permite hacer otra aproximación a la relación JoséÁngel: ambos viajan, se desplazan en el aire y tienen sueños y visiones. El cuarto capítulo calza con el primero en cuanto a que «El exilio le provoca inconvenientes al ángel» (21). Llegado a este punto, ¿por qué la situación del ángel se plantea como exilio y no como expulsión o caída? ¿Por qué se asume una categoría sociopolítica (exilio) para referirse a un ente de naturaleza celeste? ¿Cuál es la función del relato sobre el ángel en relación con la historia de los personajes, en particular con la de José, con quien se le equipara?

Por el momento, una respuesta provisional: la novela nunca nos cuenta los efectos del exilio en José a causa de la llegada al poder de los sandinistas, pero sí nos relata lo que experimenta el ángel fuera de su espacio. Dada la relación José-ángel que ya hemos destacado en los títulos de los capítulos, podemos decir que la historia del ángel sirve para llenar — a nivel diegético — la experiencia de exiliado vivida por José: su experiencia de extravío, desconcierto, temor, vértigo, trastorno, aturdimiento y pesadillas funciona como complemento de la historia no conocida de José.

La equiparación de José con el ángel es central para suplir parte de la historia de José, del mismo modo como el silencio de Augusta es suplido por una serie de indicios otorgados por la narradora para que vayamos llenando el mundo que Augusta no nos cuenta. Así como el regreso-caída de José no le produce placer-deleite-alegría, sino «desasosiego y angustia», del mismo modo al ángel le produce desconcierto, extravío y trastornos: «ahora que realizo el viaje esperado por mucho tiempo y con gran ilusión, lo estropea algo insólito. Estoy aturdido. Tal parece que he venido a soportar una pesadilla» $(54)^{6}$. A la pregunta de José sobre cómo iba a tener visiones y sueños semejante a los profetas y santos no siendo uno de ellos (17), se le corresponde, de

\footnotetext{
${ }^{6}$ También hay que señalar la relación de José con Augusta por su actitud entristecida, retraída y ensimismada: «Su mutismo le proporcionaba los más nefastos resultados» (53).
} 
forma inversa, la que se hace el ángel sobre su experiencia terrestre: «¿cómo iba a sufrir los inconvenientes de los mortales»(21). Aquel desatino, aquella desorientación y aquel extravío sufrido por el ángel el día de su caída-llegada a la tierra es también experimentado por José cuando deambula por las calles de la ciudad: «Estaba desatinado, triste, descontento con sus mismas reflexiones» (29).

Retornemos al análisis de los títulos de capítulos: el quinto nos ubica en el mundo de Augusta, quien se nos describe cómo va a ser hasta el antepenúltimo capítulo: «Augusta, callada, soporta sus miedos y recuerdos». De inmediato se ofrecen los elementos que la equiparan a José y al ángel: «Vive exiliada, aunque sólo dentro de sí misma, porque nunca ha salido de su país» (23). También encontramos el binomio dentro-mundo interior/fuera-mundo exterior que se presenta en los casos de José y el ángel. Las valoraciones son: mundo interior-negativotormentoso-angustioso/mundo exterior-positivo-placentero-tranquilo. Esto remite a dos categorías de dos planos diferentes: una de orden sociopolítico, el exilio, otra de carácter socio-psicológico, el inxilio ${ }^{7}$. Podemos reforzar la idea de Augusta con otros personajes. Así como José se exilia y Honorio se queda dentro del país, del mismo modo sucede con Victoria y Augusta, respectivamente. El lector advierte que Augusta está retratada en el nombre de este capítulo como una mujer callada y temerosa de su pasado, del mismo modo que lo están José y el ángel. Con este capítulo $\mathrm{V}$ quedamos ante un panorama en el que se conjugan lo maravilloso, lo fantástico y lo psicológico como elementos vertebradores del texto. Por lo que sabemos, la novela gira en torno a los trastornos personales y psicológicos de los personajes a propósito de los fenómenos naturales (terremotos y huracanes) e históricos (la dictadura de Somoza y la Revolución Sandinista) que sumieron al país en la pobreza, en la miseria y en la destrucción, en el desencanto y en la caída de todas esperanzas

\footnotetext{
${ }^{7}$ Se emplea este término en el sentido de aquellos que no pudiendo salir de su propio territorio por causas socioeconómicas y socioideológicas tienen que permanecer en él, incapaces de expresar convicciones y opiniones por temor a la represión.
}

178 
sociales. Este panorama pesimista se completa con la visión milenarista y apocalíptica sobre la que está construido el texto.

Los títulos de otros capítulos conservan la atmósfera fantásticomaravillosa que hemos destacado en los primeros seis. El capítulo XIII lleva a pensar que José tiene la capacidad de escrutar y leer la mente de los demás: «José se da cuenta de lo que piensan todos y está asustado» (57). El efecto «está asustado» acentúa ese poder ya que hace suponer que se espanta de poderlo hacer o de lo que descubre en la mente de los otros. Lo mismo sucede en el capítulo XXIV en que «Augusta se traslada en espíritu al paraje de la montaña donde quedó embarazada» (97): el título supone la desmaterialización sufrida por el personaje y el poder de trasportarse, como si tuviera la facultad de bilocación. En efecto, por medio de las visiones, los personajes se trasladan de un lado a otro, de un tiempo a otro, utilizando como médium cualquier elemento de la realidad cotidiana o por medio de alguna sensación producida por los datos de la realidad fáctica: el fuego, un libro, una piedra, una mirada en el espejo, el agua, el ruido de una aplanadora, una noticia, una canción, un poema. Un título que calza con la visión apocalíptica es el del capítulo XXIII: «José tiene un sueño con don Fito, donde salvan al género humano de sí mismos» $(95)^{8}$. No sólo se refuerza la idea de los sueños y las visiones, sino también el carácter mesiánico del soñador, y su estatura divina que lo equipara al ser angélico con que se ha venido asociando desde el principio.

\section{Los epígrafes}

Otro elemento paratextual son los epígrafes. Condensan y programan gran parte de los trayectos de lectura que nos permitirá la novela y cada uno de sus capítulos. Tomaré algunos como ejercicio de lectura y dejaré abierta la puerta para que otros continúen esa labor

\footnotetext{
${ }^{8}$ Según se plantea en este título, los enemigos de los que debe librarse la humanidad son don Fito y José. En ningún momento sugiere que la humanidad sea la enemiga de sí: el ser humano enemigo del ser humano, como se lee en el desarrollo del capítulo.
} 
interpretativa. El texto abre con un epígrafe-proemio que pretende sintetizar lo relativo a lo ya dicho y lo por decir: si «todo está escrito», «las páginas que vienen es lo que sigue» (7). Desde el lugar inaugural de esta palabras en el proceso de lectura de cualquier lector que lee por primera vez, lo por decir aún no está dicho, se irá desplegando conforme se transita por el texto. Pero desde el punto de vista de quien lo ha escrito, lo por decir está dicho, del mismo modo que lo por leer está leído por aquel que ha organizado la historia. El intento de ampliar la frontera de lo ya dicho se convierte en una mera ilusión, si a eso le sumamos el presupuesto de que nada se escribe desde cero y que todo texto es una relectura y una reescritura de un texto anterior, como lo es este que leemos, dada la gran cantidad de textos sobre los cuales trabaja y que sirven para organizar la trama y la historia de los personajes. Ese conjunto de literatura citada, recitada y concitada se presenta en los epígrafes que acompañan a cada capítulo.

El epígrafe del primer capítulo conduce al binomio tiempo/eternidad: para los humanos sólo es posible pensar el no tiempo a partir del tiempo. Pero de lo que se trata en el capítulo es de la irrupción de la eternidad en el plano de la temporalidad: un ángel ha caído en nuestro tiempo y esta experiencia lo ha trastornado. Aquel no tiempo exterior al tiempo, ha entrado en la historia como un elemento que servirá para explicar y darle sentido a la temporalidad: la experiencia dolorosa y de desarraigo sufrida por José en su exilio. Así, el epígrafe sugiere la orientación hacia lo religioso que funcionará como elemento vertebrador del texto: el aquí y el ahora ha sido alcanzado por la eternidad caída. Esa categoría habitada de eternidad es el alma, tal como se infiere del título: «el ángel que nos ocupa está exiliado del cielo» (9; el destacado es mío).

El segundo capítulo presenta un epígrafe que invierte lo antes planteado: ya no estamos habitado por el alma, sino deshabitado de ella: «a un éter lleno de recuerdos, se ha salido de nosotros el alma, para vernos de lejos» (11). Ya el alma no es ese otro que nos ocupa, sino ese otro que nos observa, ese otro que nos convierte en objetos de nosotros mismos. Además de remitir a un dualismo antropológico (cuerpo/alma), el epígrafe activa una serie de binomios opuestos: pasivo/activo, 
terreno/extraterreno y olvido/memoria. Ese otro que observa desde fuera parece ser lo que trastorna a José, incapaz de soportar el retorno de la memoria una vez que se repatria. En este sentido, esa alma que nos observa desde fuera vendría a ser nuestro otro yo que retorna, como se plantea en el epígrafe del tercer capítulo: «Mi otro yo no hace más que volver a mí; por fin están de vuelta todas las partes del mismo largo tiempo dispersas en el extranjero entre todas las cosas y todas las casualidades» (17). Estamos ante una escisión: José, hombre de dos orillas, ahora vuelve y se encuentra con el José que dejó cuando partió, pero que lo ve con ojos del José que retorna, no con los del José que se fue. La imposibilidad de articular estas dos realidades lo trastorna, lo enmudece como a Augusta ${ }^{9}$. José es un sujeto siniestrado, en términos freudiano: aquello conocido y familiar regresa y se vuelve ominoso.

El epígrafe del capítulo $\mathrm{V}$ nos introduce en el contexto de la confrontación armada por derrocar a Somoza y sirve para configurar los resultados de esa contienda: «la victoria es de otros». Por lo que sabemos del texto, Augusta ha quedado excluida de la distribución de poder después de haber participado en la lucha. Esta idea se pone de relieve en el epígrafe del capítulo XXII: los intentos del hombre por cambiar el mundo terminan de dos maneras: en «sórdidas dictaduras» o en «fructíferos negocios que aprovechan un puñado de cínicos que se presentan siempre como personas desinteresadas y decentes empeñadas en el bienestar del país y de sus habitantes» (89). Con ello se condensa toda la visión que el texto propone sobre el Frente Sandinista de Liberación Nacional: devela y desenmascara la visión utopista e idealista que manejan Augusta y Ernesto. El epígrafe aparece como si fuera don Fito su portavoz, dado que él es el encargado de explicarle a Augusta la

\footnotetext{
$\overline{9}$ José nada expresa sobre su experiencia de exiliado ni sobre el impacto que le causa el retorno a una patria desastrada. Su silencio ante la realidad que encuentra es sustituido por la poesía y por la música que cumplen la función de expresar sus emociones, sus sentimientos, sus penas, sus alegrías, su nostalgia, su dolor: se traspone en el arte la expresión del mundo interior, las expectativas y los sueños del personaje que vuelve después de veinte años a encontrarse con un mundo que parece anclado en el pasado (27-32).
} 
situación posrevolucionaria: robo, impunidad, ambición de poder, pobreza, miseria, malversación de fondos de las ayudas internacionales. Acudiendo a Aristóteles, le aclara la posición en la que ella puede encontrarse, entre la justicia, el error y el infortunio: «Estoy seguro que usted fue siempre justa y tuvo error e infortunio» (92). Augusta, poseída por ese espíritu revolucionario, no aceptará, por supuesto, haberse equivocado al adherirse a una causa tan utópica como la justicia social para todos.

En el mismo plano se encuentra Ernesto, el «artista ingenuo», a quien se retrata en el epígrafe del capítulo XXVI: «Las utopías políticas no son más que la visión del paraíso perdido y la ilusión de recobrarlo a costa de cualquier sacrificio, pues como dice Ciorán, 'los humanos aceptan el martirio por una quimera, más que por una verdad'» (101). A diferencia de Augusta, Ernesto pasa de la sujeción-alienación ideológica a la actitud crítica, de confiar ciegamente en el discurso del poder (102), a cuestionar todo tipo de poder (103), como don Fito (91). Su intento de liberarse del mecanismo del poder lo lleva a aceptar la actitud resignada y acomodaticia de su madrastra: «Vivamos lo que Dios nos ponga, aguantemos al que esté de turno arriba y bailemos el son que nos tocan. De todos modos, aunque tengamos el alma con el Frente Sandinista, ni siquiera sabemos si existió o fue una nube producto de nuestros deseos de justicia y que en un chaparrón se terminó». Y concluye la narradora: «Se abrazaron como en un pacto de continuar viviendo» (103-104). De manera que el texto pone en escena la lucha revolucionaria, el ascenso al poder del Frente y su caída, la caída de las utopías sociales que han sacrificado al pueblo, como una de las grandes catástrofes que han dejado a su paso desastres, destrucción, miseria y muerte ${ }^{10}$.

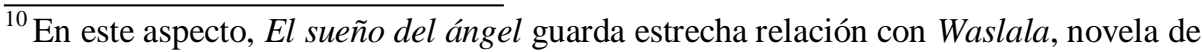
Gioconda Belli.

182
} 


\section{Un don Quijote posmoderno}

Así como hemos hecho una aproximación a las relaciones de José-Augusta-Ernesto con el ángel, también podríamos analizar la relación de don Fito con don Quijote. Don Fito no es sólo una imagen ridícula y estrafalaria, sino que encarna la figura del loco-cuerdo: tiene la capacidad de ver y oír lo que los demás no pueden y también de decir lo que los demás no se atreven. Es, además de un visionario, un profeta. No sólo su retrato físico lo asocia a un don Quijote (cuerpo flaco, canillas flacas y peludas, de esquelética y alta figura, parecía un caballero medieval), sino que sus ademanes («La saludó [a Augusta] con su rimbombante ademán») y su actitud sincera y atrevida le posibilita revelar los entretelones de la realidad socio-histórica y personal del mundo desplegado en la novela. No sólo nos conecta con el pasado y el presente, del aquí y ahora, sino que también tiene la capacidad de predecir los acontecimientos futuros dada su facultad de interpretar los signos de los tiempos. Lo único que lo distancia de la imagen del Caballero de la Triste Figura es su preocupación por la comida: va de casa en casa llevando sus «peroratas» para recibir a cambio algún bocado. La figura de don Fito encarna una doble imagen: la del cuerdo loco-don Quijote y la del Sancho hambriento que se afana por satisfacer su estómago, poniendo de relieve el carácter reversible del personaje y su aspecto carnavalesco, al fusionar en sí lo alto y lo bajo, lo superior espiritual con lo inferior material y corporal:

Augusta bordaba. Al cabo de un rato notó la mirada adormecida del hombre, la boca estirada y la nariz fruncida para absorber los efluvios procedentes de la labor culinaria, en su segundo intento de esa mañana para desayunar. Dejó su bordado y fue a la cocina... En un plato puso queso y gallo pinto..., tomó una tortilla...; de la refrigeradora sacó un pichel de mango y vertió un poco en vaso con hielo. El señor desde su asiento no sabía si era para él o para ella pero sobaba con la lengua sus labios marchitos (91). 
Pero la imagen de don Fito pone de manifiesto la relación saberhumildad y las oposiciones entre intelectualismo académico y el autodidactismo. Según el planteamiento de don Fito, los intelectuales de ahora son una mera pose exterior, «carentes de valores morales y sabiduría» (84), mientras que don Fito es la encarnación de la sabiduría y de los valores: «Su filosofía y conocimiento desconcertaba a todos... Siempre tenía respuesta hasta para los más avispados profesionales, catedráticos y estudiantes» (83). Pone en entredicho el mundo vano, superficial y light, el maquillaje de cultura y el estancamiento en el pasado de las actuales generaciones: «Añoran las páginas de Hola y a las princesas vivas o muertas de las cortes europeas, pero no leen poesía ni filosofía. No se nutren de los verdaderos escritores... la mayor escasez en una casa es la de los libros, no tienen libros... » $(84)^{11}$. Este amor por los libros y por la lectura también recuerda la imagen de Alonso Quijana que no salía de biblioteca de su casa. Si aquel viejo Quijote estaba al día en materia de libros, este nuevo Quijote está al día en los adelantos de la tecnología comunicacional: ha aprendido a manejar la computadora y navega en la red. Es un ciberquijote, integrado a la globalización y a la nueva lógica de la cultura de integrar pasado y presente para tener futuro.

\section{Visiones milenarista y apocalíptica}

El sueño del ángel se inscribe en el contexto milenarista y posee una visión apocalíptica del ser humano, del mundo y de Dios ${ }^{12}$. Consideremos primero la inminencia de cambio de siglo y cómo se

\footnotetext{
${ }^{11}$ Esta preocupación por los libros es muy parecida a la García Monge: «Ciudad o país que no lee, no anda; está dormido, anclado... Por eso no ha de faltar en cada casa, en todo vecindario algún estante de buenos libros».

${ }^{12}$ Jorge Chen Sham y María Amoretti se han referido a la lógica apocalíptica y escatológica en esta novela. Ver Chen, «Tradición genérica del sueño: las visiones en El sueño del ángel de Gloria Elena Espinoza», <www.escritorasnicaragua.org/critica?idcritica=52>; Jorge Chen y María Amoretti, «El sueño del ángel como discurso apocalíptico», $<$ http://www.escritorasnicaragua.org/critica?idcritica=50>, y «De plumas y ángeles hacia el sentido del «final» en El sueño del ángel», 〈http://www.escritorasnicaragua.org/ critica?idcritica=67> (consultados 15 de mayo 2007).

184
} 
expresa en los diferentes órdenes de la realidad. Salta a la vista la oposición entre presente y pasado: la velocidad, la perentoriedad, la aglomeración, la desorientación y la caída de todos los principios es uno de los rasgos más preponderantes en este fin de milenio que se asocia con la posmodernidad y la globalización, mientras que el pasado está asociado a la tranquilidad, a la lentitud, a la cercanía y compartir entre las personas. En palabras de José:

Antes transcurría todo tranquilo; las abuelas y bisabuelas tejían como musas para Vermeer, parloteaban en las cocinas de leña, se acostaban temprano y masticaban cuarenta veces cada bocado para hacer buena digestión. Ahora comemos de pie, a veces corremos en la calle con un emparedado... la perentoriedad en todo, hasta para ir al baño, los impuestos, los presagios, ¡uf! El problema del Y2K, la desaparición de las especies, la globalización, el calentamiento global, el terrorismo, la miseria, las drogas, los suicidios, la incertidumbre, el miedo... La vida es tan distinta en la cercanía del tercer milenio (12).

Desde el punto de vista de don Fito, que presume que el caso de José no es más que expresión de los signos de los tiempos:

La locura es un precio que pagamos por la civilización... Ocupaciones más inseguras y arriesgadas, más desilusiones, esperanzas infundadas y más luchas dolorosas para obtener lo que está fuera de nuestro alcance, o para realizar lo que es imposible, hacen ver un futuro oscuro, nebuloso. La sensación de impotencia desordena la mente, el acaso atrae el caos, los presagios del fin del mundo, todo ha provocado suicidios en masa. La humanidad está desorientada por la velocidad, asustada de sí misma, con pánico de lo que ha hecho y no puede componer (61).

Su visión de las cosas procura estar por encima de lo racional, es decir, fusiona en ella la ciencia y la fantasía, razón por la cual habla de 
que la dificultad de estos tiempos se debe a que «Presenciamos el gran cataclismo entre dos grandes tecnologías. Tratamos de acceder a la nueva con el condicionamiento psicológico y las respuestas sensoriales de la antigua... Pues, redundando un poco, el hombre trata de realizar lo nuevo con las vestiduras viejas» (86; el destacado es del texto $)^{13}$.

Augusta y don Fito nos posibilitan integrar la visión milenarista con el carácter apocalíptico del texto: el fin de los tiempos está asociado con el mito de la destrucción y el caos. La inminencia de este fin crea una concepción del ser humano, del mundo y de Dios. Por un lado encontramos a un ser humano con una conciencia de pecado, caído, degradado y supeditado a las leyes divinas que ha violado (concepción bien materializada en Augusta). También encontramos la concepción de un mundo corrupto, descompuesto. Finalmente la idea de un Dios realiza el juicio final y a dar a cada quien lo que merece. Esta concepción apocalíptica del mundo es netamente religiosa y tiene su parangón con el milenarismo medieval, época en la que también se experimentó el paso de milenio. Sobre el caso de Augusta, el texto señala:

Parecía que no vivía en los umbrales del tercer milenio. Rudolph Stadenmann la ubicaría en el periodo de la melancólica psique de la baja edad media porque un sentimiento general de catástrofe universal inminente pesaba sobre los hombres y mujeres de esa época, agravado por la obsesión de que se acercaba el fin del mundo (43; el destacado es mío).

Augusta es una mujer caída: en lugar de «construir el reino de Dios en su pueblo... lo que hizo fue fornicar» (42). Esta conciencia de

\footnotetext{
${ }^{13}$ Estas palabras de don Fito recuerdan las planteadas por Jesús: «Nadie arregla un vestido viejo con remiendos de tela nueva, porque el remiendo nuevo se encoge y rompe el vestido viejo, y el desgarrón se hace mayor. Ni tampoco se echa vino nuevo en cueros viejos, porque los cueros se revientan, y tanto el vino como los cueros se pierden» (Mateo 9, 16-17). Más adelante a don Fito se le asociará con un profeta y con Cristo.
} 
culpa la arrastra desde la infancia ${ }^{14}$ y se completa cuando desiste de su vocación religiosa que la llevaría a entregarle su virginidad a Dios para entregársela a Wodan en la Catedral: «No metas a Dios en estas cosas, que no existe... la religión es el opio de los pueblos, tu cuerpo es tuyo y es mío... mío... Tu dialéctica está supeditada a ese complejo de culpa maldito que te condena, te atormenta. Domina esa inseguridad, no tienes que pedir perdón a ningún ser superior» (44-45); el destacado es mío). Ese complejo de culpa deriva de haber cometido un sacrilegio o profanación del lugar sagrado y como el ojo de Dios lo ve todo (24) fue el primero en percatarse. Por eso su segunda entrega la realiza en la selva, bajo un árbol, con la esperanza de que Dios no la hubiera visto: «Nunca como el de la primera vez, el sacrílego, sobre las cúpulas, bajo el cielo, con el viento llevando suspiros llenos de miedo. El tiempo había pasado desde aquel otro pecado y cubierta por la sombra selvática, deseaba que Dios, esa vez, no la hubiera visto» (98). Augusta pretende buscar culpables de los desastres naturales (97) y lo único que termina es reconociendo que el mal se deriva de su pecado y el de la humanidad: «Me aniquila la duda de conseguir o no perdón, me parece que queda preso, pegado en las paredes del templo. Creo que en parte soy causante de las desgracias. El pecado de los hombres causa las desgracias» (43; el destacado es mío). En su visión sobre el terremoto «sólo escuchaba lamentos, gritos, ruidos, estallidos y llanto. Musitaba perdón... perdón... perdón... no sabía por qué, pero pedía perdón. Un sentimiento de culpa la habitaba como si fuera responsable de la destrucción» (65; el destacado es mío).

${ }^{14}$ Su nacimiento está marcado por la inminencia de la muerte en la madre: su madre la
hace responsable de que por parirla casi se muere. Esta madre autoritaria y
sobreprotectora termina ensimismándola, de modo que Augusta va cayendo en un
ostracismo que la caracterizará durante toda la historia: «Allí comenzó a silenciar su
interior, sus sentimientos, todo» (33). Esa experiencia negativa con sus padres se repite
también con el médico que la manosea y con las compañeras de colegio que la humillan
(38-39). Frente a este mundo hostil, las únicas que la confortaban eran su tía abuela (34)
y su amiga Victoria (38). De modo que Augusta sufre la reclusión no sólo física
(encerrada en el cuarto oscuro) sino también espiritual (metida en su propio silencio).
Ante esta experiencia de reclusión la hace sumergirse en la imaginación (38). 
Esta conciencia de la culpa está marcada por un pasado lleno de vivencias de dos tipos de fenómenos que tienen en común la destrucción, el caos, la pobreza, la miseria y la muerte: por un lado están los fenómenos naturales (terremoto y huracanes) y por otro el fenómeno histórico de la revolución sandinista contra la dictadura de Somoza. En todo este pasado Augusta «veía el infierno» (24). Estos dos tipos de fenómenos siempre van a aparecer uno al lado del otro o contrapunteándose. Por ejemplo, en el capítulo XIV («Augusta revive el horror del terremoto») se entrecruzan lo natural (el terremoto) y lo histórico (la dictadura de Somoza): estos elementos se presentan como cataclísmicos, la imagen que plasman en el lienzo es la ruina, el desastre, la pobreza, la destrucción y la muerte. Lo mismo se plantea en el capítulo XXII: el terremoto y el sandinismo lo que han producido es pobreza el primero y miseria el segundo. El clima general que ha creado este tipo de acontecimientos es el de la zozobra, el temor, la inseguridad. A propósito del huracán Mitch: «El miedo cundía entre la gente cuando llovía aquí, allá y acullá... El miedo... Todos tenían miedo del fin del mundo» $(97)^{15}$.

Dos factores más refuerzan este catastrofísmo de la visión apocalíptica: el sueño del ángel y la poesía leída por Augusta. El capítulo XVI («El ángel vuelve a soñar y huye de La Tierra») se refiere a que el ángel sueña «con una serpiente que crecía», se paseaba por todos los confines de la tierra y abría las fauces queriendo comerse a la humanidad: la imagen que sigue es de guerra, destrucción, desolación y muerte. Esa visión no puede ser comunicada a los hombres porque éstos aparecen envueltos en un denso humo ${ }^{16}$. Este humo les impide a los

\footnotetext{
${ }^{15}$ En una de las explicaciones que don Fito sobre el malestar de José recurre a las imágenes de los fenómenos naturales para señalar su ruptura, su desequilibrio mental: «Es posible que donde José esté con terror, pánico y lo está trasmitiendo... su mente desestabilizada, ¡zas!, se rompe como el equilibrio tectónico y iprum! el terremoto; o... el de las presiones barométricas y ipram! los huracanes... (61).

${ }^{16}$ Queda suelto el problema de la verdad velada por algún elemento: una tela, una cortina, una nube, una neblina. Los puntos suspensivos, como destejido del texto, sugieren ese mismo problema: la revelación se hace imposible porque el vidente corta su discurso, lo aplaza o simplemente deja el suspenso. Cito el asunto del hijo de 188
} 
hombres contemplar el ángel. El epígrafe de este capítulo también hace hincapié en la ceguera racional y propone la visión afectiva como única capaz de comunicarse y comprender: «Pero los ojos son ciegos. Hay que buscar con el corazón» (73. Esto recuerda a El principito). Lo mismo sucede en el capítulo XVIII: Augusta «tiembla con los versos del poeta» Rubén Darío del «Canto errante»: un poema que habla de temblores, de guerra, de terror, de la descomposición del mundo, de las señales celestes, de sus intérpretes como Nostradamus y del Anticristo. Este mismo poema le recuerda también su entrega carnal en la Catedral por medio del verso «En la iglesia el diablo se esconde», que le rememora «El artífice fue el demonio», del capítulo IX (80-81), del mismo modo que en los desastres naturales se verá la presencia del demonio (97).

Para salir de esa conciencia pecaminosa, caída y posibilitar que el mundo vuelva a tener futuro es fundamental reconocer a Dios, confesar el pecado y arrepentirse. En esta concepción, sólo es posible salvar al mundo si se busca a Dios. Como profeta de los últimos días aparece don Fito, quien llama a todos los pueblos de las diferentes etnias, religiones y culturas a convertirse a Dios y dejar de destruir el mundo. La respuesta es también universal: «En todos los confines de La Tierra entendieron las palabras y obedientes hicieron lo indicado por aquél a quien llamaron profeta, extraterrestre, ángel, demonio, judío errante, anticristo, astrólogo, charlatán; no obstante, por si acaso, cayeron de rodillas... besaron el suelo». De este modo, el mundo corrupto y pecaminoso, caído y en desgracia vislumbra «un futuro luminoso» (96), no gracias a la negación de Dios ni a la lucha por la justicia social por medio de la revolución, que sólo trajo destrucción y miseria, sino debido a la humanidad arrepentida y convertida a Dios que hace posible el nuevo mundo: los grandes ideales y las grandes utopías, según el texto, han dado paso a una visión religiosa.

Augusta: la elisión discursiva nos envuelve y no llegamos a saber nada; el texto se desteje o deja de tejerse con el propósito de volverse críptico. 


\section{El mundo erótico de Augusta}

Pasemos a la experiencia erótica de Augusta, dado el papel central que cumple en la vida de este personaje poseído y obsesionado por su caída, por su «pecado sacrílego» (41): frente a la disyunción ser de Dios o ser de Wodan, Augusta decide ser de Wodan en el espacio en que debió consagrarse a Dios, la Catedral. Su caída está acentuada por la confrontación de dos extremos: por un lado se siente aguijoneada por la necesidad de entregarse y por el otro quemada por la culpa de hacerlo, dada su vocación religiosa de ser monja. Ante esta disyuntiva, su entrega está revestida de una ceremonia en la que endiosa a su amado para mitigar la culpa, razón por la cual su caída guarda estrecha relación con la entrega a Dios:

Te quiero te amo... te idolatro... sos mi vida... soy tuya... el mejor revolucionario, el internacionalista más desinteresado y bueno del mundo, mi Ché Guevara, no puedo sentir más... Perdón Dio... Vos formás parte del reino que Dios edifica en mi país, porque sos demasiado bello para que seás malo... amame... amame... La voz entrecortada quería decirle su amor y su desesperación por entregarse, como una urgencia, una necesidad que estaba unida a la culpa que sentía por hacerlo (44).

Por eso, más adelante se le llama a Wodan «dios germánico» y «dios carnívoro» que le pide a Augusta que no le ponga por delante a ningún otro Dios: «no metas a Dios en estas cosas, que no existe» (44).

Dos elementos naturales sugieren la experiencia erótica-carnal de Augusta, relacionados con el espacio y las actividades sagradas: el fuego y el viento. En una de sus visitas al templo, «Augusta fijaba su mirada en la montaña de fuego con sus llamas alocadas... La parafina mezclada con el hollín chorreaba con sucio aspecto» (24). Este juego del viento con el fuego es similar al del viento con la ropa de ella y de Wodan mientras ambos se consumen de pasión: el acto de consumirse las candelas y de chorrear es análogo al acto de entregarse y consumirse: 
Espasmódica deliraba bajo su dios carnívoro... El aire disolvía los quejidos... Era pecado, pero seguía desnuda y cabalgaba con desenfreno por el hombre sin prejuicio que no sospechaba que para ella era su primera entrega de amor. Las ráfagas de viento casi llevaban sus ropas que servían de cama. Él estrujaba sus senos, sus piernas y el pelo alborotado parecía plumaje de paloma de las que volaban desde las puntas de los cupulines para unirse con el cielo en una cópula cósmica (45; el destacado es mío).

Esa relación entre cópula humana y cópula divina se pone de relieve en las parejas Augusta-Wodan y las torres y el cielo: «Hipnotizada miraba las torres incrustadas en el cielo, le hacían recordar momentos vividos con Wodan»(41). Así se invierte la semiótica que poseemos sobre la relación topológica arriba-cielo-masculino / abajotierra-femenino, dado que el texto sumerge los espacios en otra semiosis, invirtiendo la significación: las torres representan el principio masculino y el cielo el principio femenino. Esta erotización del espacio permite hablar de una cópula cósmica, protagonizada por el cielo y la tierra. Visto retrospectivamente, Augusta tendrá un pasado del que arrepentirse y que la sumirá en el complejo de culpa que nunca exorcizará: «Para ella, la estructura de torres achaparradas era sólo un escenario donde había protagonizado el acto impúdico» (43). Ni el amor pudo liberarla de ese fantasma, de ese monstruo, de ese demonio.

Después de Wodan, tuvo una segunda experiencia erótica con un compañero revolucionario que la dejó embarazada. Esta vez fue en la selva, bajo un tupido árbol con tal de evitar el ojo del sol-Dios:

Augusta, debajo de aquel árbol... pasó inadvertida. Al sol le costó mucho trabajo, como un flash indiscreto, mirar por algún segundo entre el tupido follaje. Un terremoto en la tierra húmeda, con helechos y árboles milenarios, raíces y troncos, gotas de agua y aguaceros, arrullaron el torrente fogoso de la entrega. Nunca como el de la primera vez, el sacrílego, sobre las cúpulas, bajo el cielo, con el viento llevando suspiros llenos de miedo. El tiempo 
había pasado desde aquel otro pecado y cubierta por la sombra selvática, deseaba que Dios, esa vez, no la hubiera visto (98; el destacado es mío).

Estamos ante una escena que recuerda otra prototípica. La evocación del paraíso de Adán y Eva se lleva a cabo por medio de dos elementos: el árbol y el pasar inadvertida por el ojo del sol, metáfora del ojo de Dios que todo lo ve, según leímos en el capítulo V: «ojo del Padre que todo lo ve. El sol deslizaba sus rayos... » (24).

Esta escena, otra visión de Augusta, recuerda la primera entrega, en la que se asocia a sí misma a la serpiente del Paraíso que hace caer a Adán: «Su lengua parecía la serpiente del Paraíso que lamía al hombre, lamía el espejismo de su amor» (45). En este caso, Wodan es asociado al primer hombre - y así lo es para Augusta, su primer hombre - y ella se relaciona con Eva. De manera que la segunda escena en la selva, bajo el árbol no hace más que completar la imagen de la primera pareja en el Edén, donde también Augusta asume la misma actitud serpentina de la primera escena: «con su lengua erecta como la de una serpiente lamía el cielo» (98). Aquí se ha sustituido a Wodan por el cielo y Augusta ha adquirido una dimensión cósmica. La idea de haber divinizado a su amado se completa, si interpretamos el cielo como el espacio de la divinidad y de lo sagrado.

\section{Hacia una lectura de lo fantástico}

La novela oscila entre lo maravilloso y lo fantástico, pero dado que los fenómenos no terminan de explicarse ni racional ni sobrenaturalmente, el texto permanece en una dimensión fantástica, dado la incertidumbre que experimentamos sobre ciertos aspectos que no quedan claros: qué le pasó a José, ¿estaba o no trastornado?, y qué pasó con el hijo de Augusta, ¿es o no es un ángel? Centraremos nuestra atención en las peripecias de estos dos personajes y su relación con la trama del texto. 
José experimenta fenómenos misteriosos que relacionan el texto con lo maravilloso, dado que se puede interpretar como efecto de su relación con el ángel. En el espacio de lo cotidiano irrumpe de pronto lo inesperado que transforma la vida normal y la lógica de las cosas: «De repente, José escuchó una voz que lo llamaba» (12). De inmediato viene la duda que nos alcanza como lectores porque nosotros tampoco llegamos a saber nada sobre esa voz percibida por José: «¿estoy dormido o despierto?» (13). Esta voz pone a dudar también de su propia personalidad, de su identidad, de su ser. La voz lo saca de sus casillas: «Soy un ser... ¿mutilado? He sido... ¿Una máscara? ¿Un doble personaje?» (15). «No sabía si permanecía despierto o quizá muerto» (19). José, desde su punto de vista psiquiátrico, ensaya varias posibles explicaciones del fenómeno: 1. «Es un ente de razón fabricado por mí mismo» (17); 2. «el cielo me produce delirio onírico» (18); 3. «Era una alucinación provocada por la altura» (20); y más tarde señala 4. «No está en mí, es algo que no está en mí» (60); 5. sus familiares dicen que está loco; 6. se rumora que posee una enfermedad contagiosa que borra la memoria; y 7. don Fito achaca su malestar a la lógica derivada de la atmósfera de fin de siglo en el que «reina la incertidumbre y el miedo al futuro» (60). Ninguna de estas explicaciones logran aclarar lo sucedido a José, razón por la cual nos quedamos con la duda, porque de un momento a otro, al recibir la noticia de que va a tener un nieto, queda sano: «ya se curó con ese angelito que le llegó» $(134)^{17}$.

También lo relacionado con Augusta está en la bruma de la incertidumbre. Podría pensarse que se debe a que ella sólo tiene alcance a su mundo pasado por medio de las visiones que someten la realidad a una serie de distorsiones y desajustes, impidiendo tener claro lo percibido o si lo que se nos cuenta está sucediendo o no. Por ejemplo, en su visión sobre el terremoto, «Augusta escuchó voces y ruidos... ¿Estaba fuera o

\footnotetext{
${ }^{17}$ Por el carácter simbólico que supone «se curó con ese angelito que les llegó», alguien podría leer el texto en clave maravillosa, dada la irrupción de lo sobrenatural para solucionar el problema que ninguna otra ciencia pudo resolver. Pese a esa posibilidad, el lector nunca llega a saber a qué se debían los trastornos de José, de modo que el texto sigue siendo fantástico.
} 
dentro del papel, del cobre, del espejo...? Eran instantáneas del tiempo que regresaba en una fantasmagoría de colores» (63). «Dejó de temblar, se incorporó sin dolor, con tos, en su atalaya. ¿Estaría viva o viendo desde la muerte? Sus ojos desorbitados querían mirar entre la negrura, pero sólo escuchaba lamentos, ruidos, gritos, estallidos y llantos» (65; el destacado es mío). Siempre encontraremos un elemento que se interpone entre el vidente y lo percibido: una nube, una cortina, un velo, una oscuridad, es lo que hemos llamado la verdad velada. Este elemento ayuda a acrecentar la duda tanto del personaje que ve como del lector que pone en entredicho lo que se le está contando bajo aquellas circunstancias.

Otro aspecto de la vida de Augusta en el que se materializa la duda es su hijo: no sabe qué fue de él, o qué relación hay con el ángel. Como lectores sólo nos queda formular hipótesis, podríamos suponer que el niño surgido de aquella entrega paradisíaca de Augusta y su compañero revolucionario murió y es este ángel exiliado de su paraíso ${ }^{18}$. Varios elementos apoyan tal hipótesis: ella es vista por el ángel que se espanta con sus ojos (21 y 23) y éste huye de esos ojos: «¿Tendría peligros un ángel? ¿Estuvo algún día en La Tierra? ¿Habrá tenido que ver con ese ser atormentado?» (47; el destacado es mío). En su visión de la Navidad, Augusta se pregunta cuántos años tendría ese niño que concibió en la montaña y se menciona al ángel (50). Más tarde, un silbato la saca de una nueva visión y el ruido se suspendió hasta el cielo «donde residía el mayor y más profundo secreto de su dolor» (77). Luego ve perderse a un conjunto de palomas y lo asocia con el sueño de los limpios: «El sueño de los limpios voló... fue con ellos, con los que murieron, perdido en la distancia, ya sin eco, sin contaminación, junto a

\footnotetext{
${ }^{18}$ Alguien podría alegar lo incoherente de esta hipótesis si nos atenemos a lo que señala el capítulo IV: «Adquirió la manía de quitarse las alas desde hace unos quinientos años..., quizás mil... » (21). Pero también debe tomarse en cuenta lo señalado en el capítulo I: «¿Cuán antiguo no observaba La Tierra? ... ¿Un sigl...?, ¿dos? ¿Cuál sería el tiempo propio con ese problema?, en la eternidad no hay tiempo» (9; el destacado es mío). De modo que el tiempo no es un parámetro a considerar ya que nos movemos en dos planos que se fusionan, como señala el epígrafe de ese primer capítulo.
}

194 
su niño ángel que está más allá de sus íntimos y más sagrados recuerdos» (94; el destacado es mío). Después, en la visión de los mártires también aparece «Un pequeño ángel naufragaba hundiéndose en a vastedad» (118) y en su conversación con Victoria, ella menciona a «mi hijo», «mi ángel» (128).

Pese a todos estos elementos, como lectores no nos queda claro el origen y la relación del ángel con Augusta. Compartimos con Victoria la misma duda, queda con la misma incertidumbre: «Se sorprendió Victoria por no tener ninguna respuesta porque Augusta siguió hablando, soslayando la pregunta, como si no la hubiera escuchado, como humo que desaparece en el aire; la revelación se volvía a esconder en lo profundo de su alma» (128; destacados nuestros). La fórmula como si nos ubica también en otro plano fuera de la realidad y nos sumerge en esa atmósfera de la bruma y el humo que impide la percepción de los fenómenos. El texto nos promete darnos más información sobre el niño, pero nunca cumple ese cometido: «Otro día le hablaría de su hijo y de otras cosas» (129). Lo que sabemos, no con certeza, es que su hijo murió en el hospital: «Nunca vio que la vi», dice Ernesto ${ }^{19}$ (104). «A su regreso [de la alfabetización] la busqué; mas, desde que salió del hospital por lo de su... estaba como ausente, las hadas la habían llevado a los sueños de azur... »(105). Aquí los puntos suspensivos sirven para establecer la duda por medio del vacío, la quebradura o el destejido del texto. Esa omisión es significativa porque amarra al lector en el suspenso, en la incertidumbre.

A pesar de estos aspectos fantásticos, el texto no se queda sólo en el plano metafísico, pues nos sumerge en un mundo histórico social concreto: los últimos veinte años después de la revolución sandinista. Se podría decir que se remonta al terremoto de 1972, nos introduce en la dictadura de Somoza, en la lucha revolucionaria y nos refiere las consecuencias económicas, sociales, políticas, culturales y psicológicas

\footnotetext{
${ }^{19}$ Puede verse aquí una relación entre Ernesto y el ángel: los dos miran-ven a Augusta, pero ella no se da cuenta de que es vista (21 y 24): «presintió aquellos ojos que había visto entre la selva de velas donde le abrasó el calor» (47).
} 
en los habitantes de Nicaragua. Debido a estas últimas consecuencias psicológicas, nos encontramos con un mundo visto desde la óptica de unos personajes escindidos y desrealizados. El sesgo ideológico queda explícito en la valoración negativa que se vierte sobre el espacio de acáNicaragua y la valoración positiva que se le adjudica al espacio de alláMiami (18-19). Esto queda más patente cuando se indica que los hijos de los revolucionarios no tienen futuro, mueren (131), mientras los hijos de los exiliados gozan de la vida y del futuro (133-134). Esta valoración recibe el aval del cielo cuando se le asigna un ángel de la guarda al nieto de José que nacerá en Miami ${ }^{20}$.

\section{Conclusión}

El sueño del ángel es la historia de una serie de caídas: la del ángel, la de la «normalidad» de José, la de Augusta en su mutismo y en sus cuevas o laberintos interiores, la del sandinismo, la de Ernesto en la resignación, la de las utopías sociales, la de los sueños, la del pueblo en la miseria como consecuencia de los desastres naturales (terremoto y huracanes) y de los acontecimientos históricos (la dictadura de Somoza y el Frente Sandinista). Esta serie abarca varios niveles: el natural, en antropológico, el axiológico y el divino. La caída de estos órdenes está planteada desde una perspectiva milenarista y apocalíptica, razón por la cual prima una visión religiosa del mundo concebido como corrupto, pecaminoso, débil, caído, que sólo se puede levantar de esa postración si busca a Dios, se arrepiente, confiesa sus pecados y se vuelve a reintegrar-

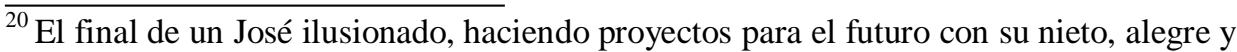
sin ningún tipo de trastornos ni de contratiempos en su retorno a Miami («Para José esta vez no hubo voces, ni nube, ni libro» (134)), contrasta con el José que vuelve por primera vez a su patria después del exilio que empieza a enfermarse y a sufrir trastornos en el avión. Podríamos interpretar esto como que Nicaragua representa problemas de todo orden que trastornan la vida de cualquiera, mientras que Estados Unidos representa la felicidad, el bienestar, la alegría y la cura de todos los males. Sólo saber que va a regresar a Miami hace que José se cure del mal desconocido. Una valoración adecuada de estos elementos nos permitiría interpretar el problema identitario en esta novela.
}

196 
fusionar todo en todos, para que se pueda decir: «El monstruo negativo desapareció y los seres del planeta, libres, pintaban su mundo en Presente inmóvil en una íntima comunión entre el hombre y el hombre, entre la naturaleza y el hombre, más una cantidad de puntos plateados que brillaron, señalando un futuro luminoso» (96; el destacado es mío). Con este cierre hemos pasado del caos al cosmos, de la catástrofe a la creación, del infierno al paraíso, de la patria terrestre a la patria celeste.

Según nuestra lectura, la condición de ángel exiliado-caído funciona como una metáfora para hablar de la condición caída del ser humano como eterno peregrino y extranjero en su propia tierra: el ángel no es más que el ser humano arrancado de su propia patria, de su propio nido y colocado en un espacio de dolor, sufrimiento y muerte. El ángel nos recuerda nuestra condición angélica, nuestra sed de infinitud y nuestro deseo de acceder a un mundo donde no existan las limitaciones terrenas: «El hombre es eterno inmigrante desde Abraham que salió de Ur; ¡qué decir!, desde Adán que salió de Paraíso y ese desarraigo, ese exilio causa dolor»; de modo que la búsqueda del cielo que realiza el ángel es análoga a la búsqueda de absoluto que posee el ser humano. Tal sed de perdón y de reconciliación con Dios se expresa en Augusta de una manera desgarradora. Tanto ella como el ángel ponen de relieve ese deseo de Dios y con el mundo abierto para liberarse de esa condición de seres caídos en desgracia. Así como el ángel sirve para expresar la angustia y la tragedia experimentada por José en su exilio, del mismo modo funciona como soporte o médium que expresa la esperanza humana de acceder a esa luz divina en el plano superior: «Avistó la luz divina en la lontananza como un punto que lo incitaba a subir y fue en pos de ella» (87).

En lugar de exaltarse el arraigo, de volver los ojos sobre la realidad, sobre la patria, sobre el nido, sobre la definición socioideológica en la que se ubican los personajes, el texto plantea la ruptura de los viejos moldes y esquemas ideológicos: José es más feliz volviendo a Miami que retornando a su propia tierra; Ernesto, que cuando revolucionario había renegado de su padre somocista, ahora se siente huérfano y se atendrá a la música que le pongan los que estén de turno en el poder; Augusta 
compra ropa en una tienda americana y retorna al círculo social aristocrático del que había renegado por hacerse sandinista y recupera su habla al confesarse con Victoria ${ }^{21}$, su amiga de abolengo que retorna del exilio, y el ángel también recupera su alegría cuando le notifican que «sería ángel de la guarda en Miami» (135). Queda el lector a las puertas de una lectura o de una relectura del problema identitario en El sueño del ángel ${ }^{22}$.

${ }^{21} \mathrm{Al}$ igual que José, Victoria es un personaje desarraigado: mientras en José el mundo que encuentra le causa desconcierto, en Victoria la realidad narrada por Augusta no la alcanza emocional, social, histórica ni verbalmente. En su conversación con Augusta se nota que las palabras de ésta sólo la alcanzan cuando se refieren a la experiencia erótica, mas no cuando Augusta habla de su experiencia histórica con el sandinismo.

${ }^{22}$ Referencias adicionales: Luis Jiménez, «Visión postcolonial, crítica tercermundista y globalización en El sueño del ángel de Gloria Elena Espinoza», <http://www.escritorasnicaragua.org/critica?idcritica=49>; Nydia Palacios, «Locura y exilio en El sueño del ángel de Gloria Elena Espinoza de Tercero», $<$ http://www.escritorasnicaragua.org/critica?idcritica=51>; Alejandro Serrano Caldera, «Para un marco filosófico de El sueño del ángel», 〈http://www.escritorasnicaragua.org/ critica?idcritica $=53>$, (consultados 15 de mayo, 2007).

198 